\title{
Interaction between Myosin and Its Substrates
}

\author{
JACOB J. BLUM ${ }^{1}$ \\ From the Mental Health Research Institute and Department of Biological Chemistry, University of Michigan, \\ Ann Arbor, Michigan; and Gerontology Branch, National Heart Institute, National Institutes of Heal'h, \\ Public Health Service, Department of Health, Education, and Welfare, Bethesda, Maryland; \\ and the Baltimore City Hospitals, Baltimore, Maryland
}

Received September 17, 1959

\begin{abstract}
Low concentrations of $p$-chloromercuribenzoate (PCMB), $\mathrm{Zn}^{++}$, or $\mathrm{Cd}^{++}$increase the ATPase and CTPase activities of myosin B but inhibit ITPase and GTPase activities. Higher concentrations of these modifiers inhibit the activities of all the nucleoside triphosphates (NTP). Dialysis against cysteine ethyl ester (CEE) increases the ATPase and CTPase activities of myosin but decreases the ITPase and GTPase activities. The temperature dependence of the maximum velocities of hydrolysis and of the Michaelis-Menten constants also differentiate between ATP-CTP and ITP. GTP. ATP and CTP confer considerable protection against thermal denaturation of myosin, while ITP and GTP confer only a small protection. The shape of the PCMB vs. NTPase activity curve is invariant to the substitution of $\mathrm{Mg}^{++}$for $\mathrm{Ca}^{++}$in the presence of $0.3 \mathrm{M} \mathrm{KCl}$ or to the substitution of $\mathrm{Na}^{+}, \mathrm{Li}^{+}$, or $\mathrm{NH}_{4}^{+}$for $\mathrm{K}^{+}$in the presence of $\mathrm{Ca}^{++}$. $\mathrm{PCMB}$ inactivates myosin at $37^{\circ}$ at a rate which is highly sensitive to the PCMB concentration. The inactivated myosin can be restored to activity by dialysis against CEE. These and other observations are interpreted in terms of a conformation change at the active site of myosin.
\end{abstract}

\section{INTRODUCTION}

A wide variety of reagents alter the ATPase $^{2}$ activity of myosin. When the effect of some of these reagents on the hydrolytic activity of myosin toward analogs of ATP has been examined, it has been found that the effect of the reagent often depends on the configuration of the substrate molecule tested (1-8). In particular it has been suggested $(1,2)$ that the amino group on position 6 of the adenine and cytosine rings plays an important role in the interaclion of myosin with ATP and with CTP. In an attempt

1 Present address: Gerontology Branch, Baltimore City Hospitals, Baltimore 24, Md.

2 Abbreviations used in this paper are: NTP and NIPP for the nucleoside triphosphates and diphosphates: A, U, I, G, and $\mathrm{C}$ representing adenine, uridine, inosine, guanosine, and cytidine, respectively; PCMB, $p$-chloromercuribenzoate; CEE, cysteine ethyl ester; Tris, tris(hydroxymethyl)aminomethane; EDTA, ethylenediamine tetraacetate; DNP, 2,4-dinitrophenol. to gain further insight into the mechanism of action of this enzyme, we have studied the effects of some sulfhydryl reagents, temperature, and various cations on the interaction between myosin and five NTP. A preliminary report of this work has already appeared (9).

\section{MATERIALS AND METHODS}

Myosin B was prepared from 5-hr. extracts of rabbit muscle, as previously described (10), and was stored at about $3^{\circ} \mathrm{C}$. in $0.6 \mathrm{M} \mathrm{KCl}$. Myosin A was prepared from 1 -hr. extracts, which were then reprecipitated three times exactly as for the preparation of myosin $B$. After the third precipitation the concentration of $\mathrm{KCl}$ was adjusted to $0.3 \mathrm{M}$, and the solution was centrifuged for $1 \mathrm{hr}$. at $28,000 \times g$ to remove actomyosin (11). Myosin A solutions were stored in $0.3 \mathrm{M} \mathrm{KCl}$ at about $3^{\circ} \mathrm{C}$.

The sodium salts of the NTP were purchased from the Sigma Chemical Company and from the Pabst Brewing Company and were used without further purification. PCMB was purchased from Sigma and was purified by the method of Whitmore 
and Woodward (12). CEE was obtained from the Schwarz Chemical Company and was used without further purification. Semidine ( $N$-phenyl-p-phenylenediamine monohydrochloride) was purchased from the Eastman Chemical Company. All other reagents were analytical grade.

Phosphate was measured by a modified FiskeSubbaRow technique, using semidine instead of aminonaphthosulfonic acid as the reducing agent (13). One hundred milligrams of semidine was put into a $100-\mathrm{ml}$. volumetric flask, moistened with a few drops of $95 \%$ ethyl alcohol, adjusted to volume by the addition of $1 \% \mathrm{NaHSO}_{3}$, stirred, and filtered. The clear filtrate was kept in a brownglass container. Semidine solutions were made twice a month or oftener. The reaction of myosin with any of its substrates was terminated by adding $3 \mathrm{ml}$. of reaction mixture to $2 \mathrm{ml}$. of $10 \%$ trichloroacetic acid. Denatured myosin was removed by filtration through Whatman 40 filter paper. $\Lambda$ half milliliter of molybdate reagent (25 g. am-

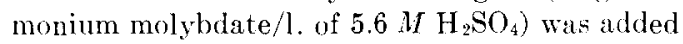
to $3 \mathrm{ml}$. filtrate, and about 80 sec. later a half milliliter of semidine solution was added. The optial density was measured at $750 \mathrm{~m} \mu$ in a Beckman model DU spectrophotometer $600 \mathrm{sec}$. after the addition of semidine. Thus all samples were exposed to acid molybdate and to semidine for the same time, thereby minimizing errors due to acid hrdrolysis of the XTP. Except when otherwise specified, activity measurements were made at $25.5^{\circ} \mathrm{C}$. in solutions containing $0.3 \mathrm{M} \mathrm{KCl}, 0.05 \mathrm{M}$ Tris, $5 \times 10^{-3} \mathrm{M} \mathrm{Ca}^{++}$, at $\mathrm{pH} 7.5$. This buffer will be referred to as standard buffer. The final concentration of NTP was $10^{-3} \mathrm{M}$.

Myosin concentrations were determined either by Kjeldahl analysis or by a modification (11) of the Folin-Biuret procedure deseribed by Lowry et al. (15).

The spectrophotometric procedure of Boyer (16) was employed to measure the concentration of $\mathrm{PCMB}$ and to follow the reaction of myosinSH groups with I'CMB.

()ther experimental procedures will be described as necessary.

\section{RESULTS}

\section{Change in -SH Grouts during Storage of Mrosin}

Mommaerts and Green (17) found that during the storage of myosin $\mathrm{A}$ there was a progressive loss of ATPase activity when measured at $\mathrm{pH} 9$ in the absence of $\mathrm{Ca}^{++}$. Botts and Drain (18) observed an exponential loss of the activity of myosin $B$ when measured at pH 8 with EDTA. Since it had

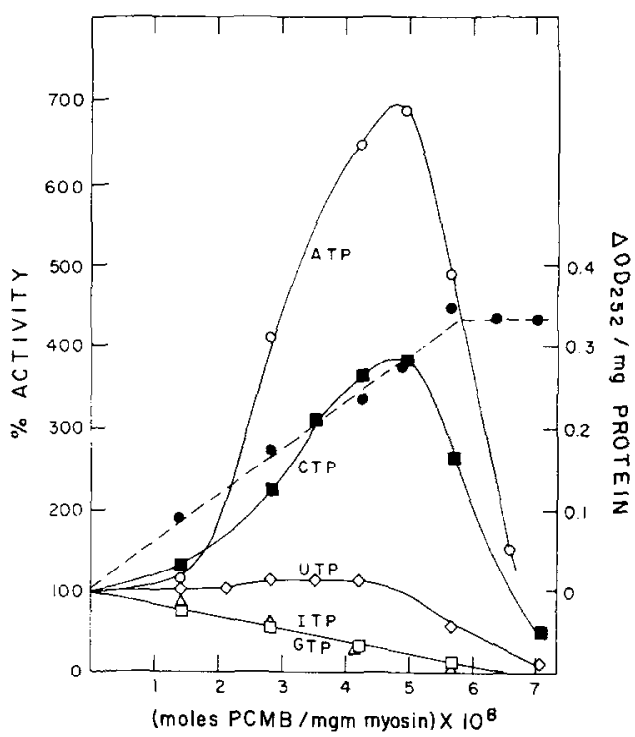

FIG. 1. Effect of PCMB on the NTPase activity of myosin. The dashed line (solid circles) shows the change in optical density at $252 \mathrm{~m} \mu$ during the titration of the - SH groups. The solid lines show the change in N'TPase activity measured at $0.6 \mathrm{M}$ $\mathrm{KCl}, 5 \times 10^{-3} M \mathrm{Ca}^{++}, 0.05 M \mathrm{Tris}, \mathrm{pH} 7.5$, on a myosin $B$ preparation 21-23 days of age.

already been shown (19-21) that there was a progressive loss of - $\mathrm{SH}$ groups of myosin during storage, a preliminary study of the effects of storage on the interaction between myosin and PCMB was indicated. Figure 1 shows a typical curve of the titration of the - SH groups of myosin B with PCMB. If the PCMB to myosin ratio at the end point is plotted against the time of storage (Fig. 2), it is found that this ratio decreases steadily, indicating a loss of PCMB-titrable groups. In view of the different effects of -.SH reagents on the different NTP (see below), and, since different myosin preparations may have different rates of loss of - $\mathrm{SH}$ groups during storage, we have used the data shown in Fig. 2 to correct only a few of the ATPase activities reported here. When such corrections were made, they are explicitly indicated. Most frequently we have chosen not to correct the data, and instead will give the age of the preparation at the time of the experiment. Much of the work to be reported here involves comparisons between experiments made a few days apart, and, since such comparisons have usually been checked on 


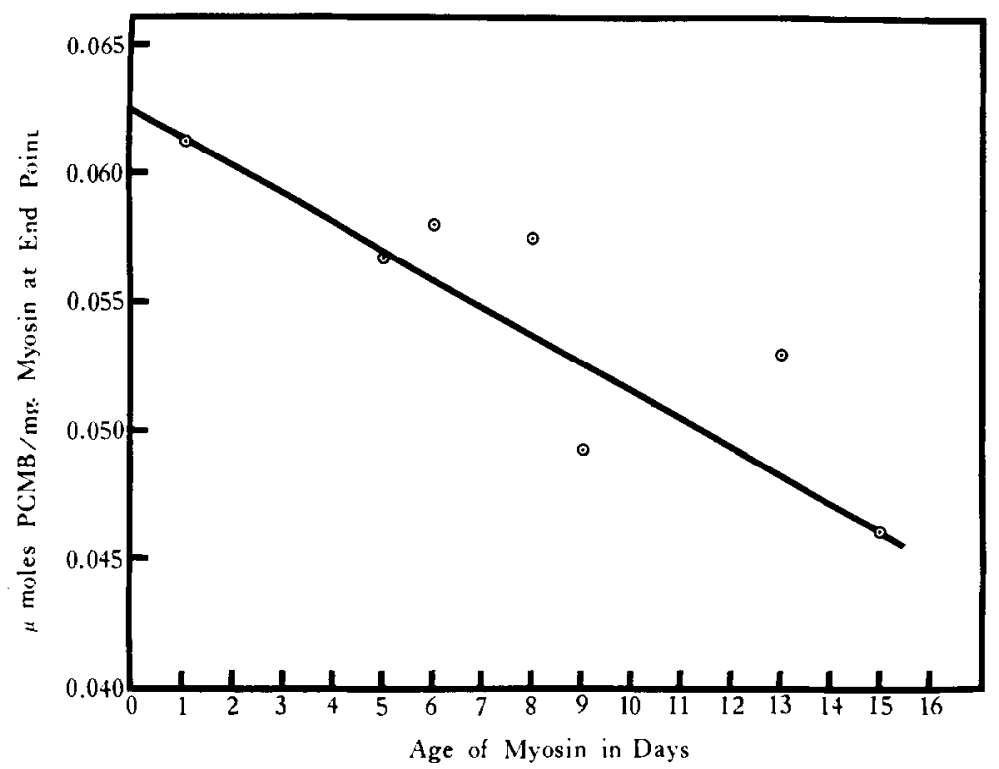

Fra. 2. Loss of $-\mathrm{SH}$ groups of myosin $\mathrm{B}$ during storage at about $3^{\circ} \mathrm{C}$. in $0.6 \mathrm{M} \mathrm{KCl}$.

several preparalions of varying age, it is believed that the conclusions reported here are not affected by the age of the myosin.

\section{EFFects of PCMB on Hydrolytic Activity of Myosin}

Low concentrations of PCMB accelerate the ATPase (22) and CTPase activities of myosin B up to a maximum (Fig. 1), wilh higher concentrations of $\mathrm{PCMB}$ then giving increasing inhibition. The ITPase and GTPase activities are, however, inhibited at all concentrations, while the UTPase activity is affected in an intermediate way. Similar results have been obtained with phenyl mercuric acetate and with 2,4-dinitrophenol by Greville and Reich (8) for myosin A at $0.4 M$ $\mathrm{KCl}$, and by W. W. Kielley (personal communication) with PCMB on myosin A at $0.05 M \mathrm{KCl}$. With myosin $\mathrm{B}$, maximum activity generally occurs between 0.03 and 0.04 $\mu$ mole $\mathrm{PCMB} / \mathrm{mg}$. protein, although occasionally, as in Fig. 1, at somewhat higher ratios. The - SH content of these preparations is about $0.06 \mu \mathrm{mole} / \mathrm{mg}$. for fresh preparations, falling to lower values during storage (Fig. 2). Myosin A preparations contain about 0.08-0.09 $\mu$ mole $\mathrm{SH} / \mathrm{mg}$. as measured by the PCMB titration, a value which is close to their total half-cysteine content (23), and their peak activity occurs at somewhat higher PCMB to myosin ratios than myo$\sin \mathrm{B}$.

The results of previous work $(1,2)$ suggested that any reagents which increased the rates of hydrolysis of ATP and CTP would decrease their reciprocal Michaelis-Menten constants, $\bar{K}$. For ITP and GTP, where it was postulated that relatively little interaction occurred between the purine ring and the enzymic site, one would expect little change in $K$. The velocities of hydrolysis of these substrates were therefore measured as a function of substrate concentration, and values of $\bar{K}$ and of $V$, the maximum velocity of hydrolysis, were obtained in the usual way from a Lineweaver-Burk (24) graph. It was found (Fig. 3 , Tables I and II) that $\bar{K}($ ATP) rapidly decreased as the PCMB concentration increased, while $\bar{K}($ ITP) remained nearly constant (possibly increasing at high PCMB concentrations). When $1 / \bar{K}(\mathrm{ATP})$ is plotted against the PCMB concentration, a linear relation is obtained (Fig. 4), suggesting that an - SH group(s) is directly concerned in the interaction of ATP and the enzymic site.

Further evidence concerning the role of - SH groups of myosin in the interaction between myosin and the purine or pyrimi- 


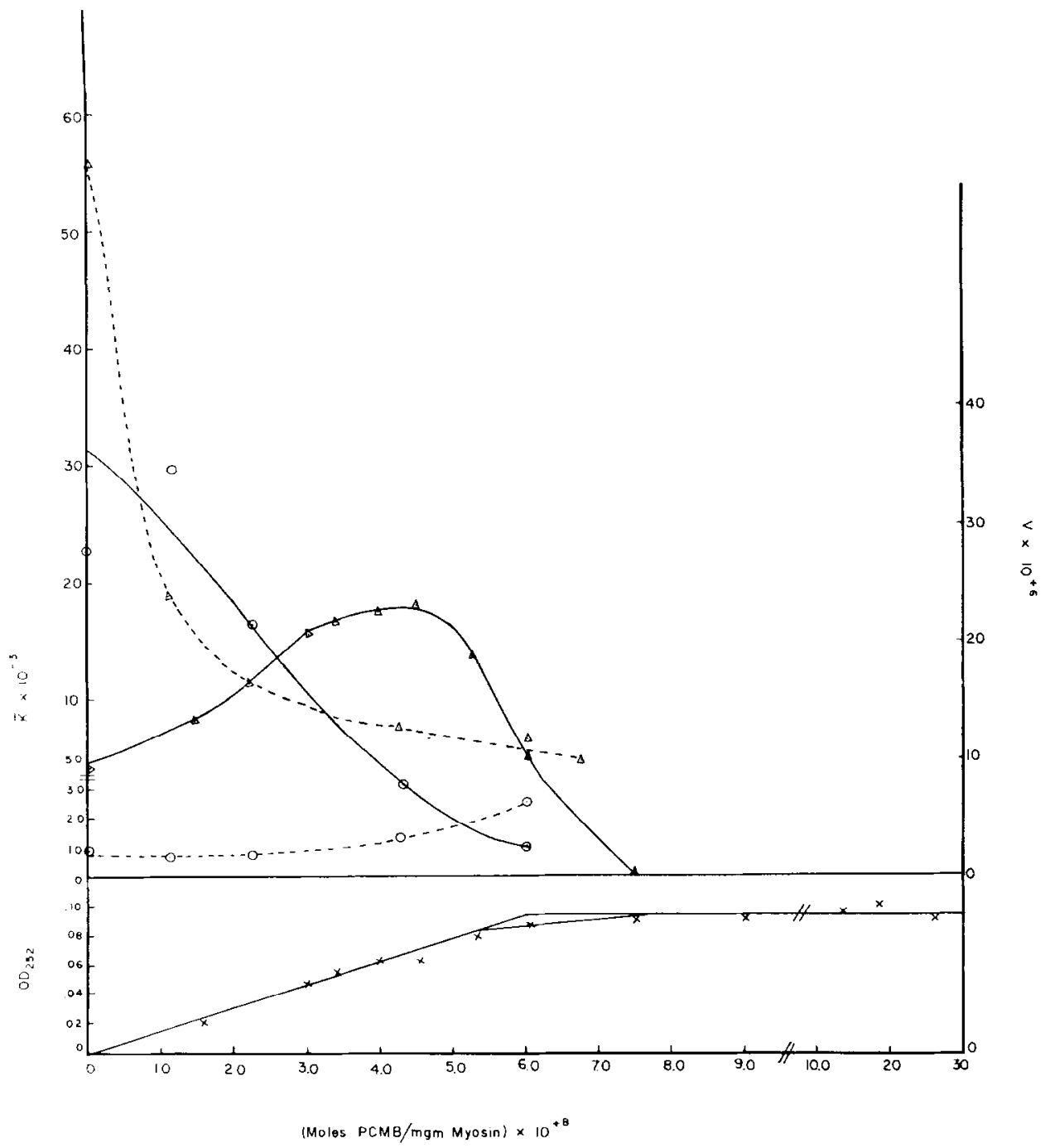

Fic. 3. Effect of $\mathrm{PC} \mathrm{C} B \mathrm{~B}$ on some kinetic parameters of myosin B. The lower graph shows the spectrophotometric titration of myosin B by PCMB. The upper graph presents the variation of $\bar{K}$ (in liters mole, dotted lines) and of $V$ (in moles P/sec. g., solid lines) for ATP (triangles) and for ITP (circles). The myosin was aged 13-16 days when the experiments with ATP were done and 20-22 dars for the ITP' experiments. The spectrophotometric titration was done on the 14 th day. Values of $\bar{K}$ were obtained from a Lineweaver-Burk plot, using the initial velocity of the reaction for at least five different substrate concentrations. Examples of such graphs for myosin $\mathrm{B}$ have been published (2). Measurements were made in standard buffer.

dine parts of the NTP was obtained by studying the effects of different ionic milieux on the kinctic constants of the cnzyme. It is well known that at high $\mathrm{KCl}, \mathrm{Mg}^{++}$causes a considerable inhibition of ATPase activity, although it slightly accelerates ITPase activity (1). The shape of the ATPase vs. PCMB curve, however, remains invariant
(Fig. 5). The large decrease in $V^{+}$is accompanied by an increase in $\bar{K}$ (Table I).

If one changes the univalent cation (keeping the total concentration at $0.3 M$ and maintaining the $\mathrm{Ca}^{++}$at $5 \times 10^{-3} M$ ), the changes that oceur in the ATPase and CTPase activities are smaller than the change caused by the substit ution of $\mathrm{M} \mathrm{gg}^{++}$for $\mathrm{Ca}^{++}$, 
TABLE I

Effect of PCMB and of $\mathrm{MG}^{++}$on the Kinetic Constants of Myosin B For ATP, CTP AND ITP

PCMB, when present, was in a concentration of $0.0326 \mu \mathrm{mole} / \mathrm{mg}$. myosin $\mathrm{B}$. The maximum CTPase activity occurred at $0.037 \mu$ mole PCMB/ mg. myosin B. Standard buffer except when $\mathrm{Mg}^{++}$ replaced $\mathrm{Ca}^{++}$.

\begin{tabular}{|c|c|c|c|c|c|}
\hline Age & $\begin{array}{l}\text { Bivalent } \\
\text { cation }\end{array}$ & PCMB & Substrate & $\bar{K} \times 10^{-s}$ & $V$ \\
\hline days & & & & l./mole & $\begin{array}{l}\mu \text { umolesf } \\
\text { sec } . \mathrm{g} .\end{array}$ \\
\hline 6 & $\mathrm{Ca}^{++}$ & - & $\mathrm{ATP}$ & 52.5 & 7.6 \\
\hline 6 & $\mathrm{Ca}^{++}$ & + & ATP & 7.4 & 21.3 \\
\hline 8 & $\mathrm{Mg}^{++}$ & + & ATP & 130. & 0.74 \\
\hline 13 & $\mathrm{Ca}^{++}$ & - & CTP & 11.8 & 3.4 \\
\hline 13 & $\mathrm{Ca}^{++}$ & + & CTP & 1.8 & 12.5 \\
\hline 14 & $\mathrm{Mg}^{++}$ & + & CTP & 57.8 & 0.66 \\
\hline 19 & $\mathrm{Ca}^{++}$ & - & ITP & 2.2 & 25.0 \\
\hline 20 & $\mathrm{Ca}^{++}$ & + & ITP & 4.1 & 4.8 \\
\hline
\end{tabular}

and here again it is found (Fig. 6) that whe over-all shape of the ATPase vs. PCMB curve is invariant. This is also true for the ITPase activity (Fig. 6). A more sensitive test of the invariancy of the shape of the curves of NTPase activity vs. PCMB concentration is to examine the ratio of the activity at a particular concentration of $\mathrm{PCMB}$ (chosen to give nearly maximal ATPase activity) to the activity in the absence of PCMB for each of the univalent cations. When this was done with the data of an experiment done at a total salt concentration of $0.6 \mathrm{M}$, it was found (Table II) that these ratios are not appreciably affected by a change in the type of univalent cation. It thus appears that the effects of univalent and bivalent cation substitutions are superimposed on an invariant, - -SH-dependent feature of the interaction between myosin and the NTP. When the PCMB concentration is enough to give maximal ATPase or CTPase activity, $\bar{K}$ (ATP or CTP) decreases to approximately the same level as $\bar{K}$ for ITP or GTP (Tables I and III and Fig. 3). Although, in the presence of such concentrations of PCMB, $\bar{K}$ is of the same order of magnitude for the various NTP, ATP and CTP are hydrolyzed much faster than are ITP or GTP, showing that the enzyme can

\section{TABLE II}

Effects of Univalent Cations and of PCMB on the NTPase Activity of

MYosin B

Myosin B, aged 28-30 days, was dialyzed overnight at $4^{\circ} \mathrm{C}$. against a buffer consisting of $0.05 \mathrm{M}$ Tris, $5 \times 10^{-3} \mathrm{M} \mathrm{Ca}^{++}, 0.6 \mathrm{M} \mathrm{KCl}, \mathrm{NaCl}, \mathrm{LiCl}$, or $\mathrm{NH}_{4} \mathrm{Cl}$, at $\mathrm{pH} 7.5$. On the following day $1 \mathrm{ml}$. myosin was mixed with $1 \mathrm{ml}$. PCMB and $10 \mathrm{ml}$. of $1.2 \times 10^{-3} M \mathrm{NTP}$. The final concentration of $\mathrm{PCMB}$ was $0.0418 \mu \mathrm{mole} / \mathrm{mg}$. myosin, a concentration just below the concentration of PCMB that would give maximal ATPase activity. The activity was measured at $25.1^{\circ} \mathrm{C}$. and is in units of micromoles $\mathrm{P} / \mathrm{sec}$. $\mathrm{g}$. The numbers in the columns headed "ratio" were obtained by dividing the activity in the presence of PCMB ( + ) by the activity in the absence of PCMB (-).

\begin{tabular}{|c|c|c|c|c|c|c|c|c|}
\hline & \multicolumn{2}{|c|}{$\mathrm{KCl}$} & \multicolumn{2}{|c|}{$\mathrm{NaCl}$} & \multicolumn{2}{|c|}{$\mathrm{LiCl}$} & \multicolumn{2}{|c|}{$\mathrm{NH}_{4} \mathrm{Cl}$} \\
\hline & 胥 & 䔍 & 苞 & 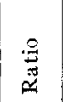 & 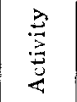 & 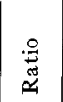 & 㟒 & 言 \\
\hline+ & 28.4 & & 26.7 & & 15.3 & & 25.1 & \\
\hline${ }^{T P}$ & 4.46 & 6.4 & 4.33 & 6.2 & 2.95 & 5.2 & 3.50 & 7.2 \\
\hline $\mathrm{TP}^{+}$ & $\begin{array}{l}3.91 \\
2.13\end{array}$ & 1.8 & $\begin{array}{l}7.41 \\
2.33\end{array}$ & 3.2 & $\begin{array}{l}6.45 \\
1.92\end{array}$ & 3.4 & \begin{tabular}{|}
5.42 \\
1.65
\end{tabular} & 3.3 \\
\hline $\mathrm{JTP}^{+}$ & & 0.81 & 9.13 & 1.1 & 6.66 & 1.2 & 7.21 & 1.2 \\
\hline- & 8.24 & & 8.10 & & 5.49 & & 5.84 & \\
\hline+ & 4.46 & & 4.94 & & 3.57 & & 4.05 & \\
\hline ITP & 13.5 & 0.33 & 12.6 & 0.39 & & 0.35 & & 0.35 \\
\hline $\mathrm{TP}^{+}$ & $\begin{array}{l}2.27 \\
9.06\end{array}$ & 0.25 & $\begin{array}{l}2.54 \\
9.68\end{array}$ & 0.26 & $\begin{array}{l}1.30 \\
6.52\end{array}$ & 0.2 & $\begin{array}{l}2.06 \\
8.93\end{array}$ & 0.23 \\
\hline
\end{tabular}

still distinguish between these two types of NTP even after PCMB has more or less eliminated the differences in $\bar{K}$.

\section{Effects of CEE on the NTPASH Activity of Mrosin B}

Morales et al. (25) have reported that when myosin $B$ is dialyzed in the cold against solutions containing CEE, an - $\mathrm{SH}$ reagenl that presumably acts rather differently than PCMB, there is a large increase in the $\mathrm{Ca}^{++}$ 


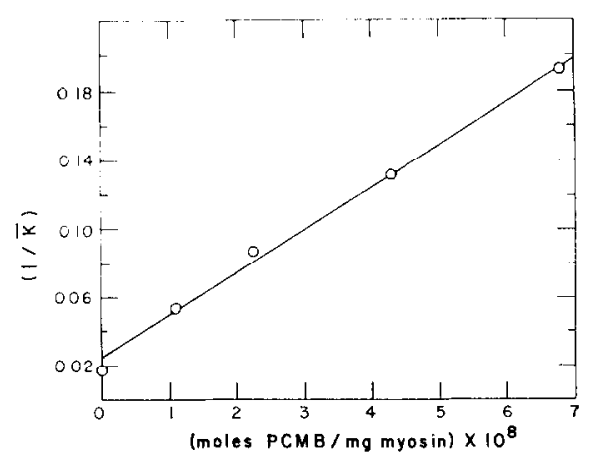

FIG. 4. Effect of PCMB on $\bar{K}(\mathrm{ATP})$. Conditions as given in legend to Fig. 3.

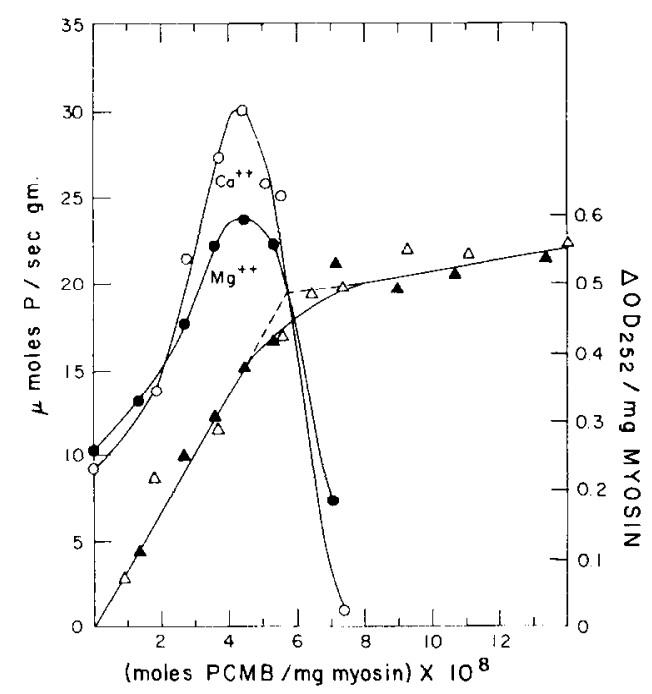

Fig. 5. Effect of PCMB on ATPase activity of myosin $\mathrm{B}$ in presence of $\mathrm{Ca}^{++}$and $\mathrm{Mg}^{++}$. Activities in the presence of $5 \times 10^{-3} \mathrm{M} \mathrm{Ca} \mathrm{Ca}^{++}$were measured on 2-day-old myosin. The activities in the presence of $5 \times 10^{-3} M \mathrm{Mg}^{++}$instead of $\mathrm{Ca}^{++}$were measured at 7 days, and have been multiplied by 30. Measurements were made in standard buffer.

activated ATPase activity. It was obviously of interest to ascertain the nature of the differential effects (if any) of CEE on other NTPase activities of myosin $B$. The results ( $k$ ig. 7 ) show that dialysis against CEE accelerates the rate of hydrolysis of CTP and ATP, but inhibits the rate of hydrolysis of ITP and of GTP. Thus treatment of myosin $B$ with CEE is similar in its effects to treatment of myosin $B$ with concentrations of PCMB up to about $0.04 \mu \mathrm{mole} / \mathrm{mg}$.

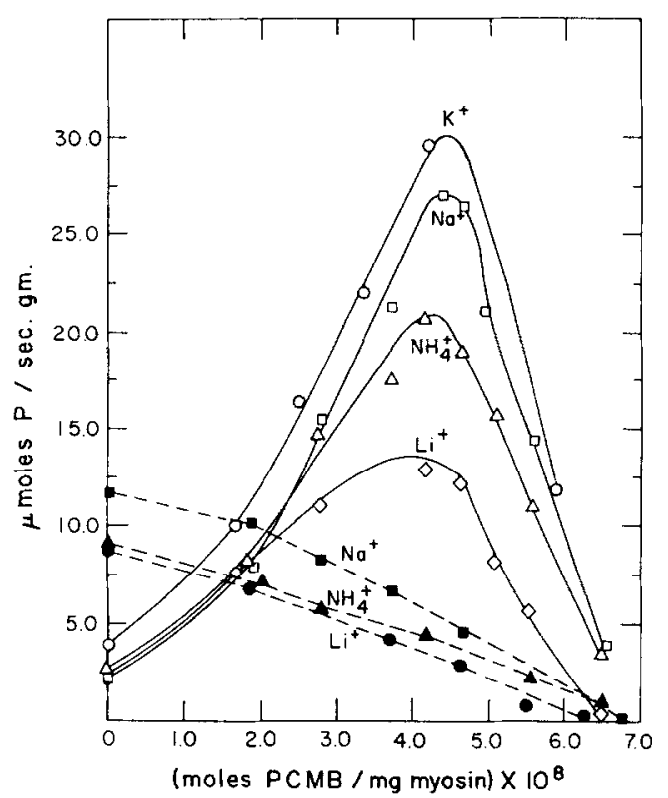

FI(i, 6. Effect of different univalent eations upon the shape of the ATPase and ITPase vs. PCMB activity curves of myosin B. Solid lines are for ATP and dashed lines are for ITP. The experiments with $\mathrm{K}^{+}, \mathrm{Na}^{+}, \mathrm{Ii}^{+}$, and $\mathrm{NH}_{4}^{+}$were done when the myosin was $1,5,13$, and 15 days old, respectively. Activities were measured at $0.6 \mathrm{~m}$

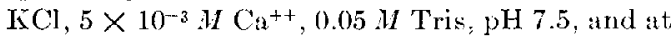
$25.5^{\circ} \mathrm{C}$.

EFHECT OF $\mathrm{ZN}^{++}$AND OF $\mathrm{CD}^{++}$ON THE ATPase and ITPase Activity of

\section{Myosin A}

Gilmour and Griffiths (26) observed that about $2 \times 10^{-5} M \mathrm{Zn}^{++}$slightly accelerated the ATPase activity of myosin $\mathrm{A}$ in $0.1 M$ $\mathrm{KCl}$ at $25^{\circ} \mathrm{C}$, but inhibited at $0^{\circ} \mathrm{C}$. A slight activation is also found at $0.3 \mathrm{M} \mathrm{KCl}$, but the same concentration of $\mathrm{Zn}^{++}$which gives a small increase in ATPase activity causes considerable inhibition of ITPase activity (Fig. 8).

Since mercurial compounds and $\mathrm{Zn}^{++}$differentially alter the NTPase aetivities of myosin, $\mathrm{Cd}^{++}$, also a member of Group IIB of the periodic table and known to bind tightly to - SH groups, was tested for its effect on the ATPase and ITPase activity of myosin $A$. As can be seen in Fig. 8, it behaves almost identically to $\mathrm{Zn}^{++}$. 


\section{TABLE III}

Effect of PCMb ox $\bar{K}$ (NTP) in the Presence of Several Different Usivalent Cations

The units of $\bar{K}$ are liters/mmole. Total salt concentration was $0.6 \mathrm{M}$. The results on GTP, $\mathrm{CTP}$, and $\mathrm{CTP}$ in $\mathrm{KCl}$ solution are on one preparation of myosin B (aged 24, 25, and 28 days, respectively). All the other data are from a different preparation of myosin $\mathrm{B}$, aged 2, 5-8, and 14-15 days, respertively, for the experiments in $\mathrm{KCl}$, $\mathrm{NaCl}$, and $\mathrm{LiCl}$ or $\mathrm{NH}_{4} \mathrm{Cl}$. A plus $(+)$ sign means the presence of $0.042 \mu$ mole PCMB/mg. myosin B.

\begin{tabular}{c|c|c|c|c}
\hline & $\mathrm{KCl}$ & $\mathrm{NaCl}$ & $\mathrm{LiCl}$ & $\mathrm{NH}_{4} \mathrm{Cl}$ \\
\hline+ & 3.0 & 6.8 & 9.1 & 4.5 \\
$\mathrm{ATP}-$ & 71.5 & 256.0 & 355.0 & 73.6 \\
+ & 1.5 & 5.7 & - & - \\
$\mathrm{CTP}$ & 15.3 & 16.2 & - & - \\
+ & 2.3 & 2.6 & 1.6 & 4.2 \\
$\mathrm{ITP}-$ & 1.2 & 3.2 & 1.6 & 10.5 \\
+ & 1.8 & 5.4 & - & - \\
$\mathrm{GTP}$ & 1.3 & 1.2 & - & - \\
\hline
\end{tabular}

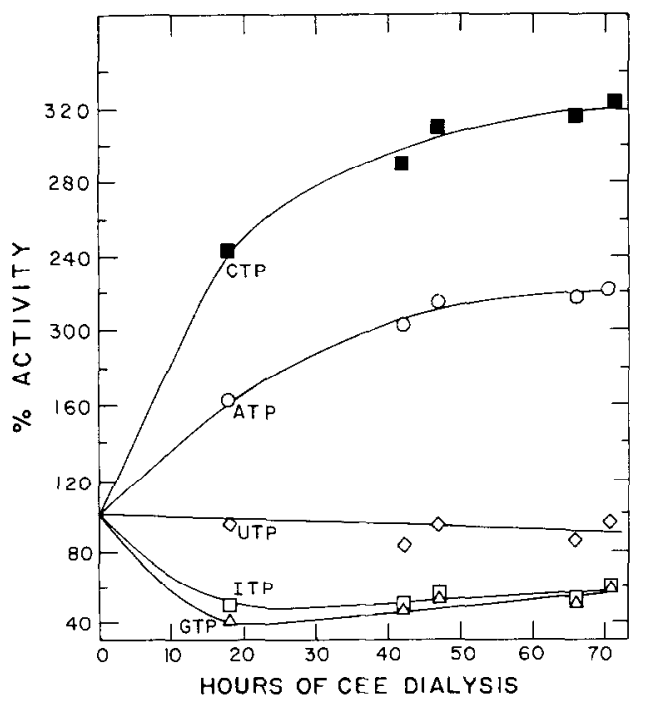

Fig. 7. Effect of CEE dialysis on NTPase activities of myosin B. A 2-day-old preparation was dialyzed against $5 \times 10^{-4} M$ CEE in standard buffer. Samples were removed at the indicated times, and their activities were measured in standard buffer.

\section{Interkelations Between ATPase Activators}

Under appropriate conditions, PCMB, CEE, EDTA, DNP, and $\mathrm{Zn}^{++}$all activate the ATPase activity of myosin A and myo$\sin B$. In the combinations so far tried [INP-EDTA (2); PCMB-LDTA (22); DNP-PCMB $(7,26) ; \mathrm{Zn}^{++}$-DNP (26)], the addition of the second activator always causes an inhibition of the activity obtained in the presence of the first activator alone. When PCMB is added to myosin B that has been dialyzed against $\mathrm{CEE}$, one observes instead of the usual activation by PCMB a pronounced inhibition (Fig. 9). When $\mathrm{Cd}^{++}$ is added to myosin $\mathrm{A}$ already activated by PCMB, the $\mathrm{Cd}^{++}$rapidly inhibits the ATPase activity (Fig. 10). Similarly, the addition of $\mathrm{Zn}^{++}$to myosin $\mathrm{A}$ already activated by $\mathrm{Cd}^{++}$causes an inhibition (Fig. 10). At low temperatures, similarly to $\mathrm{Zn}^{++}(26)$, $\mathrm{Cd}^{++}$also inhibits ATPase.

\section{EFFECTS OF NTP on Thermal. Denaturation of Myosin B}

The interaction of myosin with its substrate has consequences not only on the hydrolytic stability of the substrate molecules but also on the thermal stability of the enzyme molecule. Ljubimova and Engelhardt (27) and Ouellet et al. (28) reported that ATP protected myosin B against thermal denaturation. We have confirmed this observation and, in addition, find that whereas CTP is nearly as potent as ATP in conferring protection against thermal denaturation, both ITP and GTP are much less effective (Fig. 11). CTP is slightly more effective than ITP or GTP. When myosin B is heated with ADP there is also a considerable protection against thermal denaturation. The observed protection could not be due to small amounts of ATP synthesized during the experiment by myokinase, since a control with the maximum amount of ATP that could have been present (had there been no ATPase activity) denatured almost as fast as a control containing neither $\mathrm{ADP}^{3}$ nor $\mathrm{ATP}^{3}$ (Table IV). Neither DNP, EDTA, substitution of $\mathrm{Mg}^{++}$ for $\mathrm{Ca}^{++}$, nor changing the $\mathrm{KCl}$ from 0.3 to

${ }^{3}$ The mercurial that (Xreville and Needham (7) actually used was phenylmercuric acetate. 


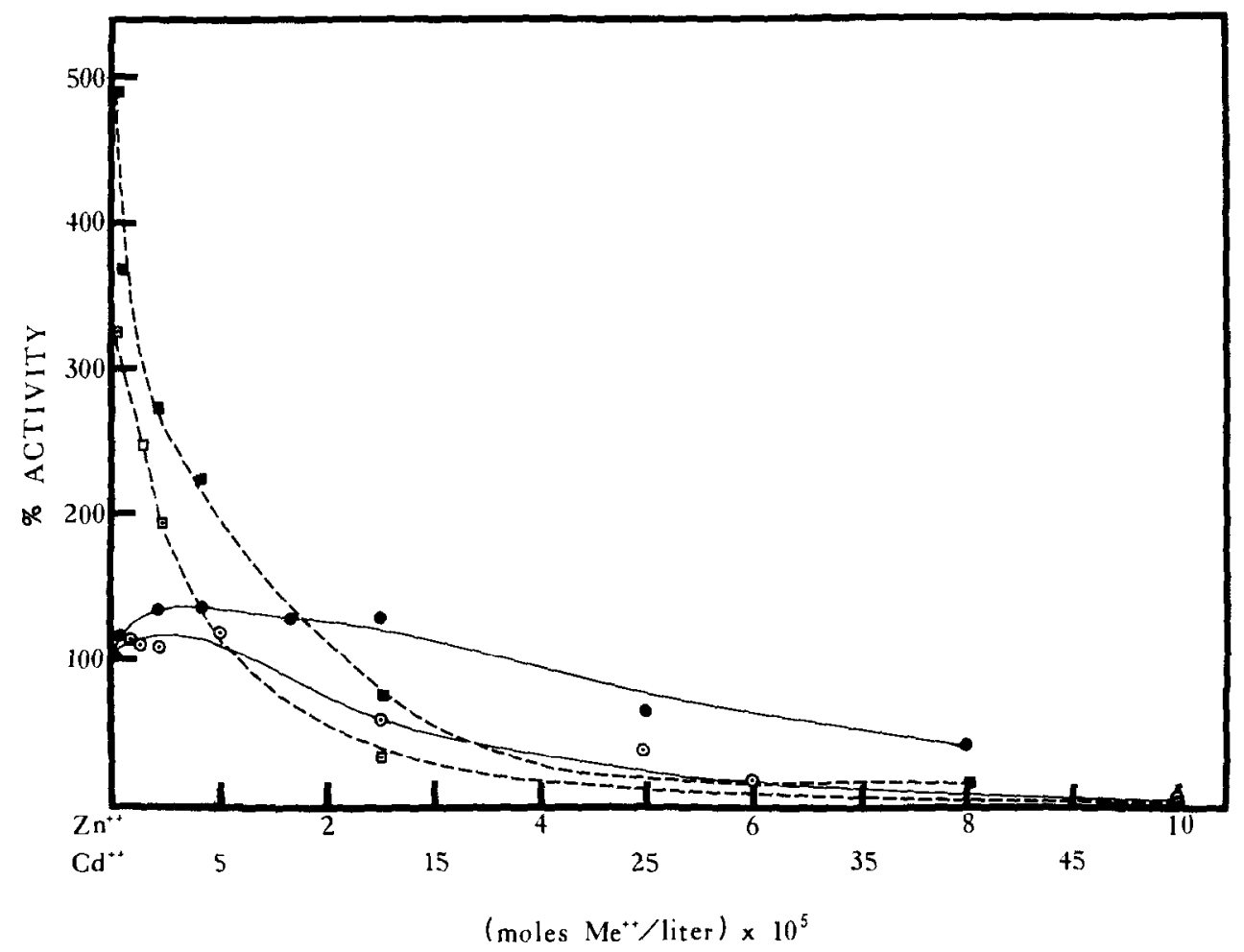

FIG. 8. Effect of $\mathrm{Zn}^{++}$and of $\mathrm{Cd}^{++}$on ATPase and ITPase activity. Activity measurements were made under standard conditions on a 7 -day-old preparation of myosin A for the experiments with $\mathrm{Zn} \mathrm{n}^{++}$and on a different 3-day-old myosin A for the experiments with $\mathrm{Cd}^{++}$. Dasher lines refer to ITP, solid lines refer to ATP. Solid symbols refer to $\mathrm{Zn}^{++}$, open symbols to $\mathrm{Cd}^{++}$.

$0.03 M$ had an appreciable effect on the rate of denaturation of myosin $\mathrm{B}$ at $37^{\circ} \mathrm{C}$.

\section{EFFECT OF P'MB ANI CEE ON THERMAL Denaturation of Mrosin B}

Since the interaction of ATP and CTP with myosin involves - SH groups and stabilizes the enzymic site with respect to thermal inactivation, it was of interest to study the effect of PCMB and of CEE on the thermal denaturation of myosin.

When myosin B is heated in the presence of PCMB, it is found that there is little change in $k_{d}^{37}$, the apparent first-order rate constant of denaturation, until the PCMB concentration approaches a value which gives maximal ATPase activity (Fig, 12). Small increments in PCMB then cause very large increases in the apparent rate of denaturation. In the presence of ATP, the value of $k_{d^{37}}^{37}$ at each concentration of PCMB is smaller than the value of $k_{d}{ }^{37}$ for the con- trol containing the same concentration of PCMB but no ATP. Thus the protection conferred by ATP is maintained even during the apparent sensitization to thermal denaturation caused by PCMB. It seemed difficult to reconcile these two observations until it was realized that, although the loss of activity during heating in the presence of PCMB obeyed first-order kinetics and, hence, seemed to be the same as a thermal denaturation, it was possible that the loss of activity could reflect a first-order reaction with PCMB. If so, it would probably be reversed by dialysis against CEE. In an experiment designed to test the reversibility of this apparent denaturation, it was found (Table V) that dialysis against CFE could increase the activity of the "denatured" enzyme by almost 200 times, restoring the activity to a level intermediate between the two control values. Hence, the rapid loss of activity observed at eoncentrations of 


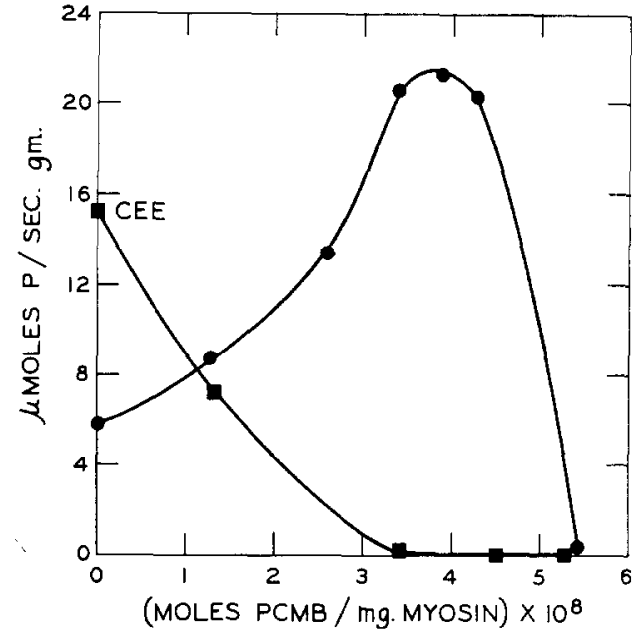

FIg. 9. Effect of PCMB on myosin treated with CEE. A solution containing $3.1 \mathrm{mg} . / \mathrm{ml}$. of a $24-$ day-old myosin B was prepared. Half of it was dialyzed against standard buffer for about $80 \mathrm{hr}$. The other half was dialyzed against standard buffer containing $5 \times 10^{-4} M$ CEE for $65 \mathrm{hr}$. and then against buffer for about $15 \mathrm{hr}$. The activities of both proteins were then measured in standard buffer at the concentrations of PCMB shown.

PCMB just above those required for peak ATPase activity (Fig. 12) are caused by the reaction of an $-\mathrm{SH}$ group(s) with PCMB.

An attempt was made to analyze the kinetics of the reaction between myosin and PCMB at $37^{\circ}$, using a treatment similar to that of Van Eys, Ciotti, and Kaplan (29), who studied the protection afforded by certain substrate analogs against the thermal denaturation of yeast alcohol dehydrogenase. The following assumptions were made: $(a)$ The enzyme (total concentration at time $t$ is $\mathrm{E}_{0}$ ) can react with $n$ molecules of PCMB, this reaction having an equilibrium constant $K$. (b) Complexes of enzyme with $n-1, n-2$, etc. molecules of PCMB are ignored. (c) Free enzyme (concentration [E]) loses ATPase activity by thermal denaturation with a first-order rate constant $k_{d}$. (d) Enzyme complexed with $n$ molecules of PCMB (concentration [E. $n \mathrm{PCMB}]$ ) loses activity by thermal denaturation (first-order rate constant $k_{d}^{\prime}$ ) and also by a first-order reaction with all $n$ of the bound PCMB molecules (rate constant $k_{1}$ ). These assumptions are formulated in the following equations:

$$
\begin{array}{r}
\mathrm{E}+n \mathrm{PCMB} \rightleftarrows \mathrm{E} . n \mathrm{PCMB} ; \\
K=\frac{[\mathrm{E} \cdot n \mathrm{PCMB}]}{[\mathrm{E}][\mathrm{PCMB}]^{n}} \\
{\left[\mathrm{E}_{0}\right]=[\mathrm{E}]+[\mathrm{E} . n \mathrm{PCMB}]} \\
d\left[\mathrm{E}_{0}\right] / d t=-k_{d}[\mathrm{~L}] \\
-\left(k^{\prime}{ }_{d}+k_{1}\right)[\mathrm{E} . n \mathrm{PCMB}]
\end{array}
$$

If we now define the relative rate of loss of activity, $R R$, as the ratio of the experimentally obtained first-order denaturation constant for any [PCMB] to the first-order constant obtained without PCMB, then the following relation can be obtained from Eqs. (1)-(3).

$$
\begin{aligned}
& \left(\frac{1}{\mathrm{RR}}-1\right)^{-1}=-\frac{k_{d}^{\prime}+k_{1}}{k_{1}+k_{d}^{\prime}-k_{d}} \\
& -\frac{k_{d}}{\left(k_{1}+k_{d}^{\prime}-k_{d}\right) \overline{K[\mathrm{PCMB}]^{n}}}
\end{aligned}
$$

Thus a plot of $(1 / \mathrm{RR}-1)^{-1}$ against $1 /$ $[\mathrm{PCMB}]^{n}$ should give a straight line of negative slope and (since $k_{1}$ and/or $k_{d}^{\prime}$ are experimentally greater than $k_{d}$ ) a negative intercept of absolute numerical value greater than unity. When the data shown in Fig. 12 are plotted in this way (Fig. 13), a straight line of negative slope is obtained. If $n$ is chosen as 1 or 2 , the intercept is positive. If $n$ is chosen as 3 (Fig. 13), the intercept is probably negative, but less than unity. The data are not accurate enough to permit a reasonable graph to be drawn for $n=4$. A possible interpretation of these findings is that about three - $\mathrm{SH}$ groups on the myosin $B$ react with $\mathrm{PCMB}$ at $37^{\circ}$ to cause a loss of ATPase activity (this assumes that the intercept is not significantly different from $-1)$. However, it is also possible that Eq. (4) is fortuitously homeomorphic to an equation which would be derived from some other kinetic scheme.

The effect of CEE on the thermal denaturation of myosin was examined in several preparations of myosin. It can be seen ( $\mathrm{Ta}$ ble VI) that myosin that has been dialyzed against CEE is less stable with respect to thermal denaturation than a control. It is worth noting that myosin A preparations in 


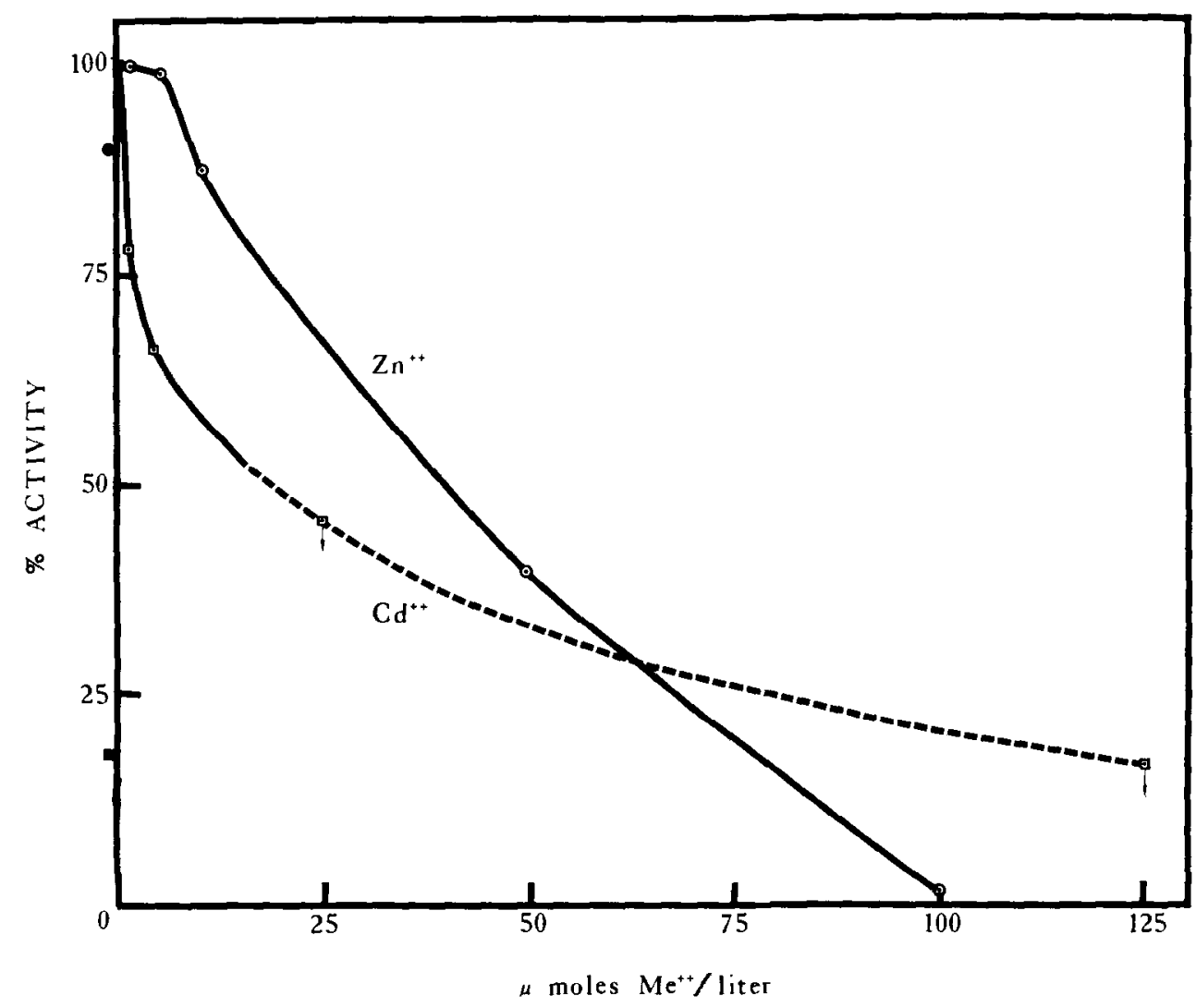

FIG. 10. Interaction between two pairs of activators of myosin ATPase. The curve with open circles shows the effect of varying concentrations of $\mathrm{Zn}^{++}$on myosin activated by a fixed $\left(10^{-5} M\right)$ concentration of $\mathrm{Cd}^{++}$; the curve with open squares shows the effect of varying encentrations of $\mathrm{Cd}^{++}$on myosin activated by a fixed $\left(0.061 \mu \mathrm{mole} / \mathrm{mg}\right.$.) concentration of PCMB. The fixed concentrations of $\mathrm{Cd}^{++}$or of PCMB were chosen to give nearly maximal activation. Solid symbols (placed slightly to the left of the ordinate for convenience) are the activities in the absence of any activator. The data on the dashed line part of the $\mathrm{Cd}^{++}$-PCMB curve are from experiments in which the ATPase activity decreased with time. The maximum rate is plotted here, and the arrows indicate that the true rate may be much smaller. Activities were measured in standard buffer on a myosin A preparation that was 9 days old for the $Z \mathrm{n}^{++}$ $\mathrm{Cd}^{++}$experiment and 14 days old for the $\mathrm{Cd}^{++}-\mathrm{PCMB}$ experiment.

general are more thernolabile than are preparations of myosin B (Table VI).

\section{EfFect of Temperature on NTPase Activity of Mrosin}

The consistently different pattern of hydrolytic activities of myosin toward ATPCTP as opposed to ITP-GTP and the differences between these substrates in their ability to protect the enzymeagainst thermal denaturation suggested that the protein might undergo a conformation change when reacting with a substrate having an amino group at position six of the purine or pyrimi- dine ring. If there were any conformation changes in the enzyme caused by interaction with one type of substrate, one might expect considerable differences in the effects of temperature on $\bar{K}$ and on $V$. The absolute reaction rate theory pertinent to an analysis of the variation of $\bar{K}$ and of $V$ with temperature is well known and may be found, e.g., in the paper by Ouellet et al. (28), who first applied this type of analysis to the myosin B-ATPase system. We shall, therefore, only summarize the meanings of the thermodynamic quantities obtainable.

If $k_{-1} \gg k_{2}$, then $\bar{K}$ is essentially an 


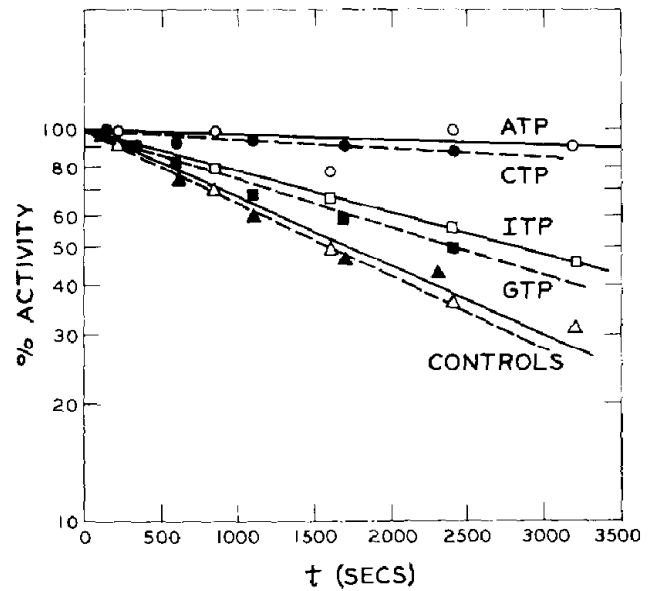

Fici. 11. Hefed of several NTP on the thermal denaturation of myosin $B$. Fixperiments on two different preparations of myosin $B$ are combined in this figure. The solid lines refer to an experiment on a 2t-day-old preparation. I)ring the heating at $37.2^{\circ} \mathrm{C}$, the myosin concentration was $0.443 \mathrm{mg} . / \mathrm{ml}$, and the initial A'TP and ITP eoneentrations were $3.0 \times 10^{-3} \mathrm{H}$, in standarl buffer. At the indicated times, f-ml, sumples were withdrawn and rapidy pipeted into test tubes partally inmersed in ice. These samples were then transferred to separate dialysis sacks and dialyzed against a total of $1500 \mathrm{ml}$. cold buffer for $+2 \mathrm{hr}$. Two milliliters of dialyzed myosin was then taken from each dialysis sack and mixed with $10 \mathrm{ml}$ of $1.2 \times 10^{-3} \mathrm{M}$ $\mathrm{ATP}$, and the activity was measured at $25.5^{\circ} \mathrm{C}$. The values of $k_{d}{ }^{3}$, the first-order denaturation constant obtained from the slope of the lines, were: control, $4.36 \times 10^{-4} \mathrm{sec}^{-1}$; ATP, $0.31 \times 10^{-4} \mathrm{sec}^{-1}$,

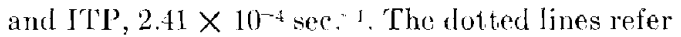
to a similar experiment on a 3 -day-old prepartition. The concentration of myosin 3 during heating was $1.59 \mathrm{mg} . / \mathrm{ml}$, and $5.0 \times 10^{-4} . \mathrm{M} \mathrm{M} \mathrm{g}^{++}$was present insteat of $5.0 \times 10^{-3} .11 \mathrm{Ca}^{4}$. The values of $k^{3} l^{37}$ were: control, $+.0 \times \times 10^{-4} \mathrm{sec}^{-1} ; \mathrm{CTP}^{-1} 0.61 \times 10^{-4}$ sec. ${ }^{1}$; ( iTP, $3.70 \times 10^{-4}$ ser. ${ }^{\cdots}$.

equilibrium constant, and a plot of $\ln \bar{K}$ against $1 / T$ is linear with a slope proportional to the heat of formation $(\Delta H)$ of the enzyme-substrate compound. A knowledge of $\Delta H$ and of $\bar{K}$ at any particular temperature then permits calculation of $\Delta S$, the entropy change caused by formation of the enzyme-substrate compound. If $k_{-1} \sim k_{2}$, the graph may not be lincar, and, if it is, the values of $\Delta H$ and $\Delta s$ may have no simple thermodynamic meanings. If $k_{-1} \ll k_{2}$ then a plot of $\ln k_{2} \bar{K}$ against $1 / T$ gives entropy
TABLI: IV

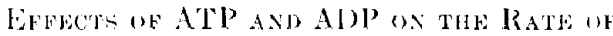
Ibintinatiox of MYosix at $37^{\circ} \mathrm{C}$.

The table presents the first-order constants for the denaturation of a 19-day-old preparation of myosin $B$ heated at a concentration of $0.15 \mathrm{mg}$./ ml. in it huffer consisting of $0.3 \mathrm{M} \mathrm{KCl}, 0.05 \mathrm{Tris}$, $5.0 \times 10^{3} . / \mathrm{Ca}^{++}$at $\mathrm{pH} 7.5$. Samples were taken from the system with ADP before and after heating, and the increase in amount of or thophosphate was measured and found to be $2.7 \times 10^{-5}$ moles $\mathrm{P} / \mathrm{l}$. in $2000 \mathrm{sec}$.

\begin{tabular}{c|c} 
Substratc & $k, l^{3 i} \times 10^{-4} \sec ^{-1}$ \\
\hline Control & -1.92 \\
$\mathrm{ATP}, 3 \times 10^{-3} \mathrm{M}$ & 0.46 \\
$\mathrm{ADP}, 3 \times 10^{-3} . \mathrm{H}$ & 3.32 \\
$\mathrm{ATP}, 3 \times 10^{-5} \mathrm{H}$ & +10
\end{tabular}

and enthalpy values pertaining to the rate constant $k_{1}$. From a plot of $h \quad F$ against $1 / T$, the ent halpy and entropy of format ion of the activated complex, $\Delta H_{2}^{+}$and $\Delta S_{2} \neq$, respectively, are obtained. Approximate values of $\Delta H, \Delta S_{,} \Delta H_{2} \neq$, and $\Delta S_{2} \neq$ were omputed from the data shown in Figs. 14 and 15 , and are presented in Table VII. The entropics (and hence the free energies) wore computed for $25^{\circ} \mathrm{C}$. If $\bar{K}$ for both ATP-CTP and for ITl'-CrT'P is an equilibrium comstant, then it is clear that, although ATP' and ("TP bind endothermically, ITP and GTP bind exothermically. Hence, the structure of the purine or pyrimidine part of the NTP molecule is a major factor in determining the binding of the NTP to the enzyme, and it, may not be eorrect to interpret the endothermic value of $\Delta I$ for $A T P$ as due to a charge repulsion between ATP and the enzymic site $(28,30)$.

Although the over-all free energy of formation of the activated complex $\left(\Delta F_{2+}+\right.$, com-

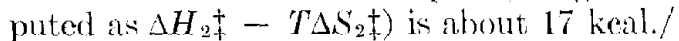
mole for all four NTl, it is evident (Table VII) that the mode of attaimment of the activated state is quite different for the two types of NTP. For ATP and (TP, $\Delta S_{2}+$ is negative; while for ITY' and GTP, $\Delta$ sot in positive. The large difference between the values of $\Delta S_{2 \ddagger}$ (about $60 \mathrm{kcal}$, mole deg.) for the tro classes of substrate an only be due to a difference in the interaction of the 


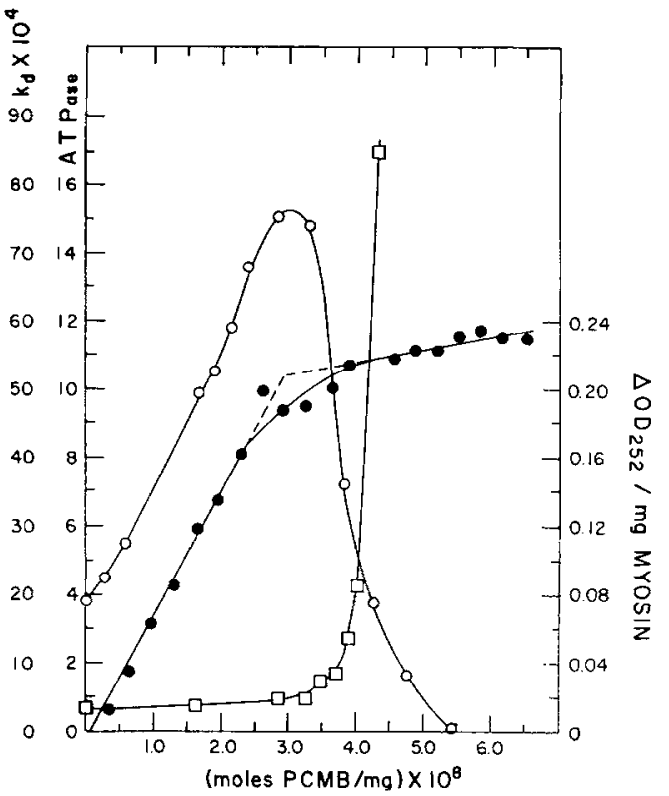

FIG. 12. Effect of PCMB on the apparent rate of denaturation of myosin $B$. The titration of the $-\mathrm{SH}$ groups (-) and the effect of $\mathrm{PCMB}$ on the ATPase activity (O), measured in micromoles $P /$ sec. g., were done when this preparation of myosin B was 2 days old. The values of $k_{d}$ ( $\square$ ), measured in units of sec. ${ }^{-1}$, were obtained by heating a solution containing $0.684 \mathrm{mg} . / \mathrm{ml}$. of 7 -dayold myosin and the indicated amount of PCMB at $37^{\circ}$. Two-milliliter samples were withdrawn at known times and were added to $10 \mathrm{ml}$. of $1.2 \times$ $10^{-3} M$ ATP at room temperature, and the ATPase activity was measured at $25.5^{\circ} \mathrm{C}$. The logarithm of the ATPase activity was plotted against the time for each concentration of PCMB, and $k_{d}$ was computed from the slope of the lines so obtained. To correct for the change in - - SH group content during the 5 days that elapsed between the measurement of the ATPase vs. PCMB curve and the $k_{d}{ }^{37}$ vs. PCMB curve, the abscissas for each measurement of $k_{z}{ }^{37}$ were multiplied by 1.14 (see Fig. 2) before they were plotted on this graph. Standard buffer was used throughout.

purine or pyrimidine ring with the protein; this suggests that the configuration of the protein at or near the enzyme site is different for the two classes of NTP.

\section{DISCUSSION}

We have previously $(1,2)$ emphasized the importance of the amino group of ATP in the interaction between this molecule and
TABLE $V$

Effect of CEE on ATPase Activity of Myosin "Denatured" by Heating in the Presence of PCMB

The concentration of myosin A (9 days' old) during heating was $0.200 \mathrm{mg} . / \mathrm{ml}$. All activities were measured at $25^{\circ} \mathrm{C}$. in standard buffer and are in units of micromoles $\mathrm{P} / \mathrm{sec}$. $\mathrm{g}$.

\begin{tabular}{l|c|c}
\hline & \multicolumn{2}{|c}{$\begin{array}{c}\text { Micromoles PCMB/mg. } \\
\text { myosin }\end{array}$} \\
& 0.079 & None \\
\hline & \multicolumn{2}{|c}{ Activity } \\
Before heating & 0.34 & 4.6 \\
After 700 sec. at 37 & $<0.03$ & 3.2 \\
After 66 hr. dialysis & 5.5 & 9.1 \\
against $5 \times 10^{-4} \mathrm{M} \mathrm{CEE}$ & & \\
\hline
\end{tabular}

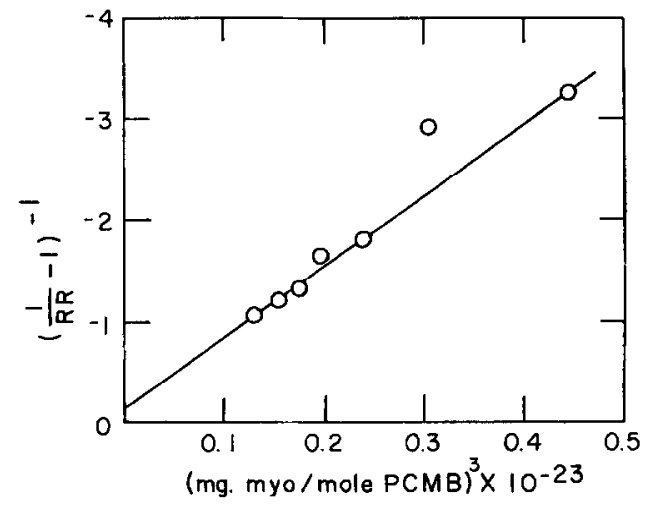

FIG. 13. This graph results from the application of Eq. (4) to the data presented in Fig. 9. For further details see text.

\section{TABLE VI}

Effect of CEE Dialysis on Rate of Thermal Denaturation of Mrosin

Each preparation was dialyzed against $5 \times$ $10^{-4} M$ CEE in standard buffer for about $60 \mathrm{hr}$. and then dialyzed against buffer for at least 6 hr. The concentrations of myosin during heating were $0.584,0.124$, and $0.603 \mathrm{mg} . / \mathrm{ml}$. for Prepns. 1, 2 , and 3, respectively. ATPase activity was measured in standard buffer.

\begin{tabular}{l|c|c|c}
\hline Preparation & $\begin{array}{c}1.20 \text { days } \\
\text { Myosin A }\end{array}$ & $\begin{array}{c}2.25 \text { days } \\
\text { Myosin B }\end{array}$ & $\begin{array}{c}3.14 \text { days } \\
\text { Myosin A }\end{array}$ \\
\cline { 2 - 4 } & \multicolumn{3}{|c}{$k_{d^{37} \times 10^{-4}\left(\text { sec. }^{-1}\right)}$} \\
Control & 6.77 & 3.64 & 7.86 \\
CEE & 9.92 & 5.13 & 9.84 \\
\hline
\end{tabular}




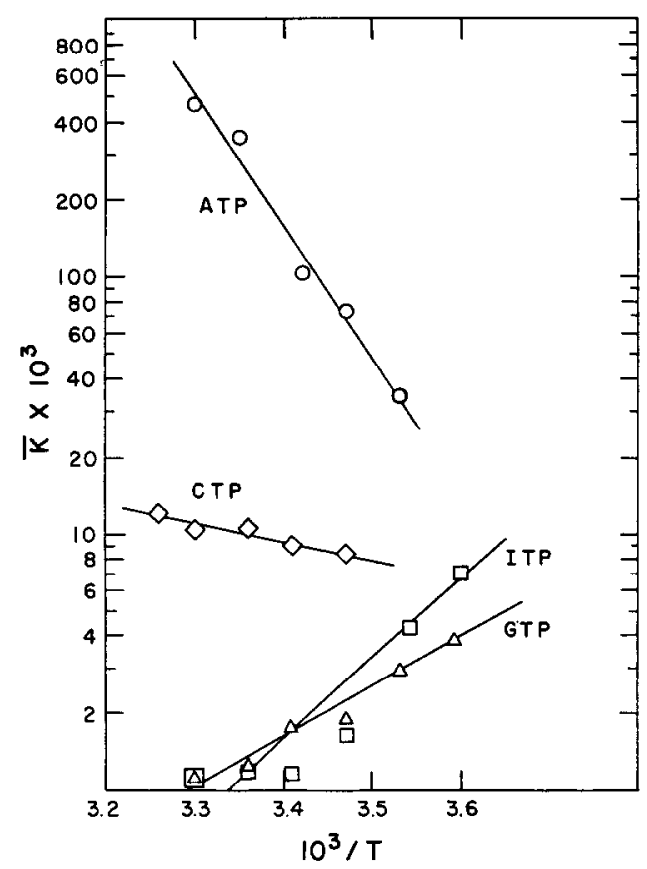

FIG. 14. Variation of the reciprocal MichaelisMenten constant with temperature. The experiments were done on myosin $B$ in a buffer containing $0.6 M \mathrm{KCl}, 5 \times 10^{-3} \mathrm{M} \mathrm{Ca}^{++}, 0.05 M$ T'ris at $\mathrm{pH}$ 7.5. The NTP concentrations ranged from about $2 \times 10^{-3} M$ to $5 \times 10^{-5} M$. The myosin and the NTP solutions were preincubated for 200 sec. at the temperature of the experiment and were then mixed and the reaction rate was measured. All rates were corrected for the loss due to thermal inactivation during the 200 -sec. preincubation, using the experimentally obtained values of $k_{d}=$ $2.34 \times 10^{-4} \mathrm{sec}^{-1}, 1.20 \times 10^{-4} \mathrm{sec}^{-1}$, and $0.25 \times$ $10^{-4} \mathrm{sec}^{-1}$ for $34.4^{\circ}, 31.9^{\circ}$, and $28.0^{\circ} \mathrm{C}$, respectively. The age of the myosin is shown in the legend to Table VII. Units of $\tilde{K}$ are liters/mole.

the enzyme. The differences between ATPCTP and ITP-GTP, as reflected in their changing sequences of $\bar{K}$ and of $V$, were assumed to be due to a difference in the degree of binding of the purine or pyrimidine ring to the site and to a consequent difference in the rate of desorption of split NDP. It was also assumed that the $\mathrm{P}-\mathrm{O}-\mathrm{P}$ bond cleavage step per se was the same for all the NTP, and that the differential effects of $\mathrm{Mg}^{++}$, EDTA, and DNP were due to changes that these substances caused in the degree of interaction of the amino group with the site. The pattern of differences in

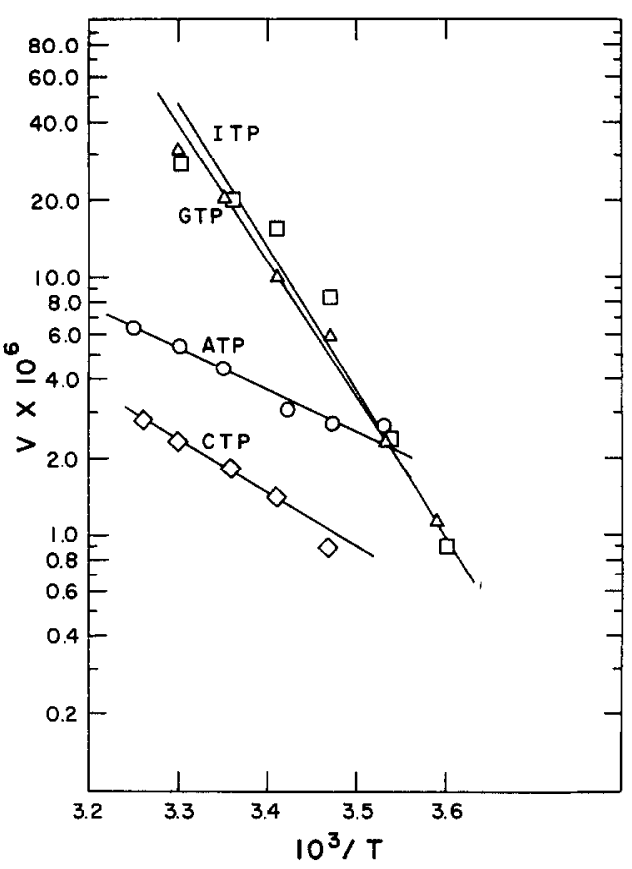

FIG. 15. Variation of the maximum velocity of hydrolysis with temperature. See legend to Fig. 14.

\section{TABLE VII}

\section{Summary of Entropies and Enthalpies Pertaining to the Hydrolysis of NTP BY Mrosin B}

The entropy and enthalpy values were computed from the data shown in Figs. 14 and 15. The values indicated with an asterisk are from the work of Ouellet et al. (28) and refer to $0.6 \mathrm{M} \mathrm{KCl}$, $10^{-3} M \mathrm{Ca}^{++}, \mathrm{pH}$ 7.0. The value of $\Delta S_{2} \ddagger$ obtained by Ouellet et al. has been recomputed for an enzyme molecular weight of 420,000 to make it comparable to the other values of $\Delta S_{2} \ddagger$ shown in this table.

\begin{tabular}{|c|c|c|c|c|c|c|}
\hline Substrate & $\begin{array}{c}\text { Age of } \\
\text { myosin }\end{array}$ & $\Delta B$ & $\Delta S$ & $\Delta H_{2 \ddagger} \ddagger$ & $\Delta S_{2} \ddagger$ & $\Delta F_{2} \ddagger$ \\
\hline & $d a y s$ & $\begin{array}{c}\text { kcal. } \\
\text { mole }\end{array}$ & $\begin{array}{l}\text { cal./ } \\
\text { mole } \\
\text { deg. }\end{array}$ & $\begin{array}{c}\text { kcal./ } \\
\text { mole }\end{array}$ & $\begin{array}{l}\text { cal./ } \\
\text { mole } \\
\text { deg. }\end{array}$ & $\begin{array}{c}\text { kcal./ } \\
\text { mole }\end{array}$ \\
\hline ATP & $9-10$ & 26 & 112 & 6 & -37 & 17 \\
\hline CTP & $21-22$ & 4 & 39 & 9 & -29 & 18 \\
\hline ITP & $15-16$ & -15 & -23 & 26 & 33 & 16 \\
\hline GTP & $17-18$ & -9 & -3 & 24 & 26 & 16 \\
\hline ATP* & - & 8 & 49 & 12.4 & -15.3 & 17 \\
\hline
\end{tabular}

behavior of myosin with respect to the two classes of substrates is summarized in Table VIII. The most satisfactory hypothesis to explain these differences is to assume that 


\section{TABLE VIII}

\section{Efrects of Various Treatments on the Myosin-NTPase System}

These effects refer to a system of myosin in standard buffer at $25^{\circ} \mathrm{C}$. UTP is always intermediate between ATP-CTP and ITP-GTP at this high salt concentration. Some of these effects change at low salt concentrations and at low temperature. Thus PCMB (26), $\mathrm{Zn}^{++}(26), \mathrm{DNP}(26)$, and $\mathrm{Cd}^{++}$inhibit the splitting of ATP at $0^{\circ}$ in concentrations which cause acceleration at $25^{\circ}$. UTP is hydrolyzed faster than the other NTP in the presence of $\mathrm{Ca}^{++}$at low ionic strength (3), and EDTA inhibits all the NTPase activities at low ionic strength (40).

\begin{tabular}{l|l|l}
\hline \multicolumn{1}{c|}{ Reagent } & \multicolumn{2}{|c}{ Substrate } \\
\cline { 2 - 3 } & \multicolumn{1}{|c}{ ATP-CTP } & \multicolumn{1}{c}{ ITP-GTP } \\
\hline PCMB $, \mathrm{Zn}^{++}, \mathrm{Cd}^{++}$ & $\begin{array}{l}\text { Low concentrations uccelerate, } \\
\text { high concentrations inhibit } \\
\text { Acceleration }\end{array}$ & Only inhilitiou \\
CEE & Strong inhibition & Inhibition \\
Mg & Acceleration & Slight acceleration \\
DNP & Acceleration & No effect \\
EDTA & Large protection & Inhibition \\
Heating at $37^{\circ}$ & $\bar{K}$ increases with $T$ & Small protection \\
Temperature & $\bar{K}$ decreases with $T$ \\
\hline
\end{tabular}

ATP and CTP induce a conformation change in the neighborhood of the enzymic site. In a sense, then, the enzyme that hydrolyzes ATP and CTP is not quite the same as the enzyme that hydrolyzes ITP and GTP. When myosin hydrolyzes ITP and GTP, it appears to be a "simpler" enzyme. Thus -SH reagents like PCMB, CEE, $\mathrm{Cd}^{++}$, and $\mathrm{Zn}^{++}$ inhibit it, $\mathrm{Ca}^{++}$and $\mathrm{Mg}^{++}$accelerate the hydrolytic rate in a manner analogous to their behavior on the non-enzymic rate of hydrolysis of the NTP (2), and DNP has no effect. When myosin hydrolyzes ATP and CTP, however, a different activated complex seems to be formed (Table VII), in which, judging from the unusual effects of PCMB, $\mathrm{CEE}, \mathrm{Cd}^{++}$, and $\mathrm{Zn}^{++}$, there has been a change in the conformation of the site and, in particular, of the configuration of the -SH groups. Gilmour and Griffiths (26) interpreted their data on the effects of $\mathrm{Zn}^{++}$, DNP, PCMB, and EDTA on myosin A ATPase at $0^{\circ}$ and at $25^{\circ}$ in terms of changes of polymerization-aggregation reactions of the myosin. They emphasized that such changes in physical state could change the accessibility of important - SH groups. Concurrently with the present work, Levy, Sharon, and Koshland (31) studied the effects of temperature on the myosin A ATPase-DNP system in the presence of $\mathrm{Ca}^{++}$or
$\mathrm{Mg}^{++}$and postulated that myosin can exist in two forms which have different conformations at the active site, ATP stabilizing one form and DNP preventing this stabilization. Guthe and Brown (32) have also suggested that myosin $B$ can exist in two configurations, the active configuration being stabilized by high pressures.

Although the postulated conformation change helps clarify the differential effects of CEE, PCMB, EDTA, $\mathrm{Zn}^{++}, \mathrm{Cd}^{++}$, and DNP on the rates of hydrolysis of the two classes of NTP, it does not explain the effects of any of these substances individually nor does it give any indication of the structure of the site. The observalion (Table II and Figs. 5 and 6) that the shape of the PCMB-NTPase curve is invariant to changes in ionic conditions suggests that some of the $-\mathrm{SH}$ groups are concerned in adjusting the overall conformation of the site and do not exert a direct influence on the rate of lysis of the $\mathrm{P}-\mathrm{O}-\mathrm{P}$ bond. Presumably, concentrations of PCMB up to about $0.04 \mu \mathrm{mole} / \mathrm{mg}$. progressively prevent the conformation change usually brought about by ATP and CTP, so that these substrates then have values of $\bar{K}$ comparable to the values of $\bar{K}$ for ITP and GTP (Fig. 3 and Table III). Higher concentrations of PCMB appear to fix the protein in some inactive conformation. CEE be- 
haves like PCMB with respect to the groups involved in the NTP-dependent conformation change, but apparently cannot react with the - SH group(s) associated with the loss of enzymic activity. Another observation which may have some bearing on the structure of the site is that in all pairs so far tested, the addition of any of these activators to a myosin-NTPase system containing any other of these activators causes only an inhibition. This cannot be explained on the basis of competitive binding for activating sites and probably reflects some important property of the enzyme which might not be unrelated to the invariance of the NTPase vs. PCMB activity curve. Further work will be necessary to gain insight into the significance of interactions between the various activators.

We have so far discussed the effects of all these reagents as if they acted exclusively on $-\mathrm{SH}$ groups. It is clear that this is not necessarily the case, since EDTA and DNP may not interact with - SH groups at all, while the metal ions undoubtedly react with histidine residues (33) as well as with $-\mathrm{SH}$ groups. The emphasis placed here on the role of the $-\mathrm{SH}$ groups is not meant to exclude the participation of other groups in the postulated conformation change.

The change in the properties of the $-\mathrm{SH}$ groups undoubtedly has significance for the interaction between myosin and actin, as has been emphasized by Railey, and Perry (21). The importance of the conformation change for the involvement of the - $\mathrm{SH}$ groups in the contraction of the psoas fiber model is evident from the ability of $\mathrm{Cd}^{++}$, $\mathrm{Zn}^{++}, \mathrm{PCMB}$, and CEE $(34,35)$ to cause the relaxation of fibers in the presence of $\mathrm{Mg}^{++}$and ATP, and from the ability of various other $-\mathrm{SH}$ reagents to prevent shortening (36). It is interesting to note that the myonemes of Vorticella, which contract upon the addition of $\mathrm{Ca}^{++}$, are relaxed by ATP but not by ITP (37). Hoffmann-Berling (37) has shown that although salyrgan (a mercurical -SH reagent) does not affect the $\mathrm{Ca}^{++}$-induced contraction of the myonemal model, it can interfere with the ability of ATP to cause relaxation. Thus in this system also there seems to be an important interre- lation between the amino group of ATP and -SH groups on the contractile protein.

The change in configuration of the $-\mathrm{SH}$ groups may also be of importance in an understanding of the initial burst of ATPase activity characteristic of myosin (38). Tonomura and Kitagawa (39) have pointed out that gross physical changes do not appear to be involved in the initial burst of activity, but a change in configuration at the site could easily escape detection in light-scattering or viscosity experiments.

\section{ACKNOWLEDGMENTS}

I would like to dedicate this paper to the memory of my beloved wife, Natalie Blum.

The work reported here was initiated and much of it was completed with the aid of Grant No. RG4917 from the National Institutes of Health and with the assistance of E. Felauer. The remainder of this work has been done at the Baltimore City Hospitals with the assistance of P. Buchanan.

\section{NOTE ADDED AFTER MANUSCRIPT WAS COMPLETE}

We have now found that cupric ion $\left(\mathrm{Cu}^{++}\right)$is comparable to $\mathrm{PCMB}$ in its effects on myosin, i.e., low concentrations accelerate and high concentrations inhibit ATPase activity, while ITPase activity is inhibited at all concentrations.

\section{REFERENCES}

1. BLum, J. J., Arch. Biochem. Biophys. 65, 486 (1955).

2. Blum, J. J., and Felauer, E., Arch. Biochem. Biophys. 81, 285 (1959).

3. Hasselbach, W., Biochim. et Biophys. Acta 25, 365 (1957).

4. Kielley, W. W., Kalckar, H. M., and BradLEY, L. B., J. Biol. Chem. 219, 95 (1956).

5. Blum, J. J., Abstr. Intern. Congr. Biochem., Brd Congr., Brussels, 1955.

6. Perry, S. V., and Grey, T. C., Biochem. $J$. 64, 184 (1956).

7. Greville, G. D., and Needham, D. M., Biochim. et Biophys. Acta 16, 284 (1955).

8. Grevilte, G. D., And Reich, E., Biochim. et Biophys. Acta 20, 440 (1956).

9. Blum, J. J., Federation Proc. 18, 13 (1959).

10. Botts, J., and Morales, M. F., J. Cellular Comp. Physiol. 37, 27 (1951).

11. Pontzenl, H., Z. Nalurforsch. 66, 75 (1950).

12. Whitmore, F. C., and Woodward, G. E., "Organic Syntheses Coll.," Vol. 1, p. 159. John Wiley and Sons, Inc., New York, 1941. 
13. T)ryer, R. L., Tammes, A. R., AND Rocth, J. I, J. Biol. Chem. 225, 177 (1957).

14. (ielint, M. K., Von Hippel, P. H., SchachManx, H. K., and Morales, M. F., J. Am. Chem. Soc. 81, 1393 (1959).

15. Lowry, O. H., Rosebrough, N. J., Fark, A. L., ann Raydate, R. J., J. Biol. Chem. 193, 265 (1951).

16. Boyer, P. D., J. Am. (hem. Soc. 76, 4331 (1954).

17. Mommaer's, W. F. H. M., and Greex, I., J. Biol. Chem. 208, 833 (1954).

18. Botts, J., and Drain, G. F., JR., Conf. on Chem. of Muscular Contraction, Tokyo, 1958, ग. 33 .

19. Meni, J. W., Science 99, 518 (1944).

20. Greienstein, J., and Eidsall, J. '., J. Biol. Chem. 133, 397 (1959).

21. Balley, K., ANo PERRY, S. V., Biochim. et Biophys. Acta 1, 506 (1947).

22. Kielley, W. W., and Bradley, I. B., J. Biol. Chent. 218, 653 (1956).

23. Kominz, D. R., Hough, H., Symonos, P., And LAKI, K., Arch. Biochem. Biophys. 50, 148 (1954).

24. Lineweaver, H., and Burk, D., J.Am. Chem. Soc. 56, 658 (1934).

25. Murales, M. F., Osbahr, A. J., Martin, H. Is, AnI) Chambers, R. W., Areh. Biochem. Biophys. 72, 54 (1957).
26. Gilmour, D., axo Griffiths, M., 1rch. Biochem. Biophys. 72, 302 (1957).

27. Ljubimova, M. N., and ENGelliardt, V. A., Biokhiniya 4, 716 (1939).

28. Ouellat, L., LAIUler, K. J., ANo Morales, M. F., Arch. Biochem. Biophys. 39, 37 (1952).

29. Van EYs, J., CiotTr, M. M., ANI Kapian, N. O., Biochim. et Biophys. Acta 23, 581 (1957).

30. Morales, M. F., Botts, J., Blum, J. J., Axi Hill, 'T. I., Physiol. Revs. 35, 475 (1955).

31. Levy, H. M., Sharon, N., and Koshland, D. E., JR., Federation Proc. 18, 273 (1959).

32. (Gurne, K. F., Ano Brows, D. E. S., J. Cellular Comp. Physiol. 52, 79 (1958).

33. Lal, H., and RaO, M. S. N., J. Am. Chem. Soc. 79, 3050 (1957).

34. Watanabe, S., Conf. on Chem. of Muscular Contraction, Tokyo, 1958, p. 95.

35. IIAsselbach, W., $Z$. Naturforsch. 86, 212 (1953).

36. Portzent, H., Biochim. et Biophys. Acta 14, $195(1954)$.

37. Hoffmann-Bereing, H., Biochim. et Biophys. Acta 27, 247 (1958).

38. Weber, A., and Hasselbach, W., Biochim. et Biophys. Acta 15, 237 (1954).

39. Tonomura, Y., and Kitagawa, S., Biochim. et Biophys. Acta 27, 16 (1957).

40. Bowen, W. J., Axl) Kerwix T. D.. I. Biol. Chem. 211, 237 (1954). 